\title{
ESTÁDIOS DE DESENVOLVIMENTO EMBRIONÁRIO E LOCALIZAÇÃO DO EMBRIÃO ZIGÓTICO EM SEMENTES DE CITROS ${ }^{1}$
}

\author{
VALTEMIR GONÇALVES RIBEIRO², MOACIR PASQUAL ${ }^{3}$, JOSÉ DARLAN RAMOS ${ }^{3}$, EDUARDO BEARZOTI ${ }^{4}$ \\ e SANTOS D'ANGELO NETO5
}

\begin{abstract}
RESUMO - Objetivou-se estudar o comportamento de embriões zigóticos e nucelares aos 120, 130, 140 e 150 dias após serem efetuadas hibridações controladas entre a laranjeira 'Natal' (Citrus sinensis Osb.) e o parental masculino Poncirus trifoliata (L.) Raf. Em cada data, as sementes foram removidas, e os embriões excisados foram caracterizados em estádios de desenvolvimento (globular, cordiforme, torpedo e cotiledonar); coloração (clorofilado ou não); e localização na semente (próximo à micrópila ou mais interiormente). A partir dessas características, foram construídas tabelas de contingência para testar hipóteses de independência entre elas, mediante o teste exato de Fisher e $\chi^{2}$ (qui-quadrado). Relações de dependência foram verificadas entre as características: estádios de desenvolvimento embrionário com a localização na semente; estádios de desenvolvimento embrionário com a natureza da plântula (zigótica ou nucelar); e entre natureza da plântula com a localização do embrião na semente. Verificou-se que os embriões zigóticos excisados de frutos com 130 a 150 dias da hibridação controlada, localizam-se, em grande maioria, próximos à região micropilar da semente, em estádio globular e cordiforme de desenvolvimento.
\end{abstract}

Termos para indexação: cultura de tecidos, melhoramento de plantas, polinização, poliembrionia.

\author{
EMBRYO DEVELOPMENT STAGE AND THE LOCATION \\ OF EMBRYO ZYGOTIC IN THE SEED OF CITRINE
}

\begin{abstract}
Controlled hybridizations between 'Natal' orange variety (Citrus sinensis Osb.) and male parent Poncirus trifoliata (L.) Raf. were performed in order to study zygotic and nucellar embryos behaviour at 120,130,140 and 150 days. At very date the seeds were removed and the embryos excised to characterize: development stage (globular, cordiform, torpedo and cotyledonal); colour (with or without chlorophyll); and location in the seed (close to the micropyle or more internal in the seed). From these characteristics contingency tables were evaluated to test independency hypothesis through Fisher test and $\chi^{2}$ (chi-square). Dependence relationships were observed between the following characteristics: stages of the embryo development with location in the seed; stages of the embryo development with the seedling nature (zygotic or nucellar); between the plant nature with embryo location in the seed. It was observed that the most of the zygotic embryos at globular and cordiform stages were located close to the micropyle in the seed, behaviour at 130 to 150 days after pollination.
\end{abstract}

Index terms: tissue culture, plant improvement, pollination, polyembryony.

\footnotetext{
${ }^{1}$ Aceito para publicação em 11 de dezembro de 1998. Apoio financeiro do CNPq e FAPEMIG.

${ }^{2}$ Eng. Agr., M.Sc., Embrapa-Centro Nacional de Pesquisa de Uva e Vinho (CNPUV), E. E. de Jales, Estrada da Barra Bonita, s/n, Caixa Postal 241, CEP 15700-000 Jales, SP. Bolsista do CNPq

${ }^{3}$ Eng. Agr., Dr., Dep. de Agricultura, Universidade Federal de Lavras (UFLA), Caixa Postal 37, CEP 37200-000 Lavras, MG. Bolsista do CNPq. E-mail: mpasqual@ufla.br

${ }^{4}$ Eng. Agr., Dr., Dep. de Ciências Exatas, UFLA.

${ }^{5}$ Eng. Agr., M.Sc., Dep. de Engenharia Florestal, UFLA.
}

\section{INTRODUÇÃO}

Entre os obstáculos relacionados aos trabalhos de pesquisa visando à obtenção de novos híbridos em Citrus e gêneros afins, destacam-se a esterilidade masculina, incompatibilidade, longo período pré-reprodutivo, alta heterozigose, complexidade dos mecanismos genéticos e a ocorrência da poliembrionia. 
Os embriões adventícios são originados de células individuais do óvulo, externas ao megagametófito, sendo as células que darão origem ao embrião adventício independentemente da estrutura do saco embrionário (Koltunow, 1993).

As células que formarão o embrião nucelar começam a se desenvolver primeiramente na região da chalaza, em seguida na região da micrópila e ao longo da lateral do saco embrionário. Entretanto, o crescimento dos embriões adventícios ou nucelares não ocorre na chalaza, mas quase que exclusivamente nas proximidades da micrópila (Buck \& Walker, 1985). Tais características, segundo Wakana \& Uemoto (1988), parecem ser decorrentes da restrição de nutrientes na região da chalaza ou por algum mecanismo relacionado à composição do endosperma, que inibe a divisão de células iniciais nesta localidade.

Os embriões de origem tanto sexual como nucelar, até atingirem o estádio de plântulas, assumem aspectos morfológicos característicos, como o globular, cordiforme, torpedo e cotiledonar, o que dificulta a separação entre si (Pasqual \& Pinto, 1988).

A época da iniciação do desenvolvimento dos embrióides tem sido questionada. A fecundação, segundo Spiegel-Roy \& Kochba (1980), ocorre de três a quatro semanas após a fertilização, e a divisão do zigoto inicia-se logo a seguir. Embriões de sementes imaturas de tangerina 'Satsuma' (C. unshui Marc.) polinizada por $P$. trifoliata (L.) Raf. mostraram desenvolvimento satisfatório quando isolados aos 90 e 120 dias da fertilização. Embrióides globulares foram encontrados em óvulos de tangerina 'Nagpuri' (C. reticulata) com 55 dias, a contar da polinização, enquanto não houve evidência da iniciação destes primórdios em laranja 'Azeda' (C. aurantium L.) 100 a 120 dias após a polinização, estando o zigoto em estádio globular ou cordiforme (Rangan et al., 1969).

O gênero $P$. trifoliata (L.) Raf. é muito empregado na produção de híbridos quando a variedade receptora é poliembriônica, pois seus descendentes herdam folhas trifoliadas e com pecíolos alados distintamente dos embriões nucelares. Embora eficiente, o uso de $P$. trifoliata no controle da poliembrionia, restringe em muito o aproveitamento da ampla variabilidade genética existente em Citrus e gêneros afins (Soares Filho et al., 1994).
A formação do embrião zigótico inicia-se após a fecundação da oosfera por um dos núcleos gaméticos do grão de pólen (Ferri, 1990). Pelo fato de a oosfera situar-se próximo à micrópila, supõe-se que o embrião sexual permaneça neste local durante determinada fase de seu desenvolvimento embrionário, e que o seu distanciamento da micrópila deve ser limitado pela presença dos embriões nucelares, também em desenvolvimento, se ele se deslocar para o interior da semente durante a sua maturação, em uma variante poliembriônica.

O objetivo principal deste estudo foi diferenciar o embrião sexual dos nucelares, por meio de suas localizações na semente durante o desenvolvimento embrionário, a contar da data da polinização controlada.

\section{MATERIAL E MÉTODOS}

Os experimentos foram realizados no Setor de Fruticultura e Laboratório de Cultura de Tecidos da Universidade Federal de Lavras, MG, no período de setembro de 1994 a junho de 1995.

Plantas adultas de laranjeiras 'Natal' (Citrus sinensis Osb.) e do gênero Poncirus trifoliata (L.) Raf., apresentando bom estado fitossanitário, foram selecionadas respectivamente, como progenitores feminino e masculino com vistas aos trabalhos de hibridação.

Botões florais de 'Trifoliata', no estádio de balão, foram coletados e armazenados em placa-de-petri por 48 horas, até a liberação dos grãos de pólen. As polinizações tiveram início em 30/9/1994 e foram polinizadas flores de seis plantas, em um total de 208 cruzamentos intergenéricos. Tomou-se o cuidado de executar as operações nas horas de insolação mais brandas, ou seja, até as 9h e, no período da tarde, após as $16 \mathrm{~h}$.

Flores de laranjeira 'Natal' foram emasculadas e polinizadas, sendo, em seguida, protegidas com saco de papel e etiquetadas, eliminando-se as demais, permanecendo apenas uma flor por ramo.

Das 208 flores polinizadas, dez foram de fato fecundadas, e destas, seis frutos sofreram queda fisiológica. Os frutos foram coletados para análise ao completarem 120, 130, 140 e 150 dias após hibridação, sendo avaliadas as seguintes características físicas: peso da matéria fresca, peso da matéria seca, número de lóculos, número de sementes por fruto, diâmetro longitudinal e diâmetro transversal do fruto. 
No Laboratório de Cultura de Tecidos da UFLA, as sementes foram removidas e tratadas com álcool $70 \%$ por dois minutos, e, em seguida, com hipoclorito de sódio $1 \%$, por 15 minutos. Em câmara de fluxo laminar contínuo, os embriões pertencentes a cada semente foram excisados e inoculados individualmente em tubos de ensaio contendo alíquotas de $15 \mathrm{~mL}$ do meio nutritivo MS (Murashige \& Skoog, 1962) acrescido de $60 \mathrm{~g} \mathrm{~L}^{-1} \mathrm{de}$ sacarose, aferindo-se ao valor de $\mathrm{pH}$ 6,2.

No ato da inoculação, foram anotadas as seguintes características: estádio de desenvolvimento embrionário (globular, cordiforme, torpedo e cotiledonar), coloração dos embriões (clorofilado ou não) e a localização do embrião na semente (próximo à inserção micropilar ou mais interiormente)

Os embriões permaneceram em ausência de luminosidade por 48 horas, sendo depois levados à sala de crescimento, à temperatura de $27 \pm 1^{\circ} \mathrm{C}$ com fotoperíodo de 16 horas e intensidade luminosa de $35 \mu$ moles $\mathrm{m}^{-2} \mathrm{~s}^{-1}$. Os embriões germinados, ao atingirem o estádio de plântulas, foram classificados quanto à origem (sexual ou nucelar) pela presença ou não de folhas trilobadas e pecíolos alados.

Os 39 embriões coletados foram agrupados em uma única classe, visando obter uma ampla visão do desenvolvimento embrionário nesse período. A partir das características avaliadas, foram construídas tabelas de contingência de dupla entrada, para testar relações de dependência entre elas, duas a duas. Para tanto, foi utilizado o teste de $\chi^{2}$ (qui-quadrado), agrupando as classes cordiforme e torpedo, para evitar ocorrências de freqüência esperada menor do que 5 . No caso das características natureza da plântula (zigótica ou nucelar) e localização na semente, por se tratar de uma tabela de contingência 2 x 2, foi aplicado o teste exato de Fisher (Pimentel-Gomes, 1987).

\section{RESULTADOS E DISCUSSÃO}

A Tabela 1 apresenta as características físicas dos frutos aos 120, 130, 140 e 150 dias de idade. O fruto obtido 120 dias após a polinização não continha sementes e, possivelmente, assim se desenvolveu por incompatibilidades inerentes ao cruzamento intergenérico, ou pelo pequeno número de dias na formação do fruto. A quantidade de sementes no fruto pode variar de acordo com a fertilidade, o clima, a hereditariedade, e a fatores evolucionários e fisiológicos (Soares Filho et al., 1995).

Observa-se, ainda pela Tabela 1, que os frutos de 130 dias após a polinização, comparados aos de 140 dias, obtiveram valores superiores para as características físicas diâmetro longitudinal, peso da matéria fresca e seca, e número de sementes e de embriões. Os maiores ganhos observados podem estar relacionados à maior síntese de fito-hormônios responsáveis pela multiplicação e alongamento celular, devido ao maior número de sementes (3) e sobretudo de embriões (20) encontrados no fruto de 130 dias. O número de embriões contidos numa semente é influenciado também pela cultivar, pelo estado nutritivo do fruto, pelos fatores ambientais e pelo clone polinizador (Soares Filho et al., 1995). O balanço hormonal de frutos em desenvolvimento pode afetar o crescimento do pericarpo. Guardiola et al. (1993), após aplicar ácido giberélico e benziladenina onze dias antes da antese, observaram maior crescimento de frutos jovens. Talon et al.

TABELA 1. Características físicas apresentadas pelos frutos obtidos do cruzamento entre $C$. sinensis Osb. com P. trifoliata (L.) Raf., aos 120, 130, 140 e 150 dias após a polinização controlada. UFLA, Lavras, MG, 1997.

\begin{tabular}{lcccc}
\hline Característica física dos frutos & \multicolumn{4}{c}{ Dias após a polinização controlada } \\
\cline { 2 - 5 } & 120 dias & 130 dias & 140 dias & 150 dias \\
\hline Diâmetro longitudinal $(\mathrm{cm})$ & 4,30 & 4,30 & 4,00 & 4,60 \\
Diâmetro transversal $(\mathrm{cm})$ & 3,20 & 3,80 & 4,00 & 4,20 \\
Peso da matéria fresca $(\mathrm{g})$ & 33,30 & 35,98 & 32,66 & 36,50 \\
Peso da matéria seca $(\mathrm{g})$ & 2,70 & 4,63 & 3,26 & 2,75 \\
Número de gomos & 8 & 9 & 10 & 10 \\
Número de sementes & 0 & 3 & 2 & 3 \\
Número de embriões & 0 & 20 & 4 & 15 \\
\hline
\end{tabular}


(1992) relatam a existência de concentrações variáveis de fito-hormônios nos ovários de cultivares com diferentes habilidades partenocárpicas.

Os frutos de 130, 140 e 150 dias de idade possuíram 20, 4 e 15 embriões por semente, respectivamente. Destes, 26 embriões germinaram e as plântulas apresentaram folhas iguais às da planta-mãe, e três não germinaram; dos dez embriões restantes, três apresentaram folhas trilobadas, sendo, portanto, embriões de natureza sexual, e sete germinaram, originando plântulas descaracterizadas morfologicamente.

Embriões imaturos podem germinar precocemente, não passando pelos estádios normais da embriogênese, originando plântulas fracas e mal formadas, sendo a germinação precoce caracterizada por um período de rápidas divisões celulares não acompanhadas por alongamento celular (Pasqual \& Pinto, 1988).

Embrióides raramente germinam se não permanecem unidos ao nucelo, calo ou outros embrióides, e ao atingirem o tamanho de 3 a $6 \mathrm{~mm}$, necessitam ser individualizados em meio de cultura fresco, para que tenham continuidade em seu processo de desenvolvimento (Pasqual \& Pinto, 1988). Se individualizados, há proliferação de embrióides pelo processo de gemação (Esan, 1973), na maioria dos casos a partir de seus hipocótilos ou células superficiais (Kochba et al., 1972). A alta atividade meristemática dos tecidos jovens do embrião, em fase de diferenciação celular, é observada inicialmente quando o zigoto sofre a primeira divisão, direcionando uma célula à formação do suspensor, e outra, através de divisões celulares freqüentes, ao embrião (Esau, 1974; Ferri, 1990). Logo, pode ter ocorrido em certa fase do desenvolvimento embrionário a clivagem do embrião e a conseqüente manifestação in vitro de vários embriões a partir de um único inoculado.

Como dos cruzamentos efetuados foram desenvolvidas oito sementes, foi esperado igual número de embriões zigóticos. Segundo Moreira \& Pio (1991), as sementes pertencentes aos frutos dos citros freqüentemente contêm embriões desenvolvidos de origem nucelar, além do zigótico, exceto de variedades monoembriônicas. Os três embriões zigóticos que alcançaram o pleno desenvolvimento nas três sementes relatadas (Fig. 1), encontravam-se no estádio cotiledonar, caracterizado pelas baixas exigências exógenas para germinar e desenvolver. Supõe-se, portanto, que os cinco híbridos restantes estão entre os embriões que não germinaram ou que ao germinar originaram plântulas mal formadas.

Considerou-se a possibilidade da existência de somente um embrião zigótico em cada semente formada (Moreira \& Pio, 1991); entretanto, Medina Filho et al. (1993) relatam a possibilidade de existirem mais de um embrião sexual por semente, denominando-se poliembrionia monozigótica e dizigótica, respectivamente devidas à clivagem do embrião sexual e pela presença de dois gametófitos em um único óvulo.

Os estádios de desenvolvimento embrionário e a localização na semente mostraram relação de dependência significativa pelo teste de $\chi^{2}$, com $\propto<0,01$ (Tabela 2). Embriões em fases de menor desenvolvimento situam-se mais próximo à micrópila, antagonicamente aos mais desenvolvidos. Isso sugere que o desenvolvimento embrionário ocorra neste sentido, possivelmente pelo maior espaço físico disponível no interior da semente, ou pelas necessidades nutricionais dos embriões em relação ao endosperma, que está em maior porção no sentido

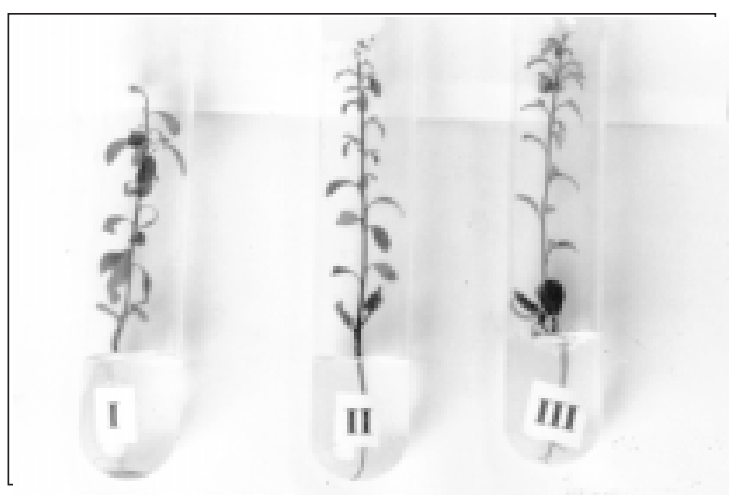

FIG. 1. Plântulas zigóticas nos respectivos estádios de desenvolvimento embrionário e suas localizações no interior da semente: I e II cotiledonar / no interior da semente; III cotiledonar / na região micropilar da semente. UFLA, Lavras, MG, 1997. 
da chalaza, para que possam atingir todos os estádios do desenvolvimento embrionário e também crescerem. Pela Fig. 2 visualiza-se a distribuição dos embriões quanto aos estádios de desenvolvimento embrionário em relação às regiões da micrópila e do interior da semente. Esses dados estão de acordo com os obtidos por Maheshwari \& Rangaswamy (1958), que relatam a origem e o desenvolvimento de embrióides na extremidade do nucelo.

A Tabela 3 especifica a localização dos embriões zigóticos e nucelares na semente. Essas características apresentaram relação de dependência significativa, de acordo com o teste exato de Fisher $(\propto<0,08)$. Observa-se que cinco dos oito embriões sexuais encontram-se na região micropilar da semente. Esse dado é embasado pela localização da oosfera na estrutura do óvulo próximo à micrópila (Maheshwari \& Rangaswamy, 1958; Ferri, 1990; Damião Filho, 1993), delegando à região micropilar o local de origem e de desenvolvimento inicial do embrião zigótico.

Pode-se fazer inferências de que na faixa de 130 a 150 dias após a fertilização, os embriões híbridos situam-se, em grande maioria, na região micropilar da semente em estádio globular de desenvolvimento, não tendo sido ainda translocados para dentro da semente, possivelmente pelo suspensor ou pela ação dos embriões nucelares (Maheshwari \& Rangaswamy, 1958; Damião Filho, 1993). A Fig. 3 retrata a posição do embrião globular que se acredita ser o zigótico, na região micropilar da semente. Observou-se, nesses embriões, distintamente aos demais, uma coloração esverdeada intensa. Outro aspecto verificado foi o maior intumescimento em relação aos demais em mesmo estádio de desenvolvimento embrionário, e estarem firmemente ligados aos tecidos adjacentes, acarretando uma maior dificuldade na excisão.

A relação entre os estádios de desenvolvimento embrionário e natureza zigótica ou nucelar das plântulas foi verificada pelo teste de qui-quadrado $(\propto<0,05)$, conforme demonstra a Tabela 4 . Pela Tabela 3, observa-se que os cinco embriões zigóticos localizados na região micropilar da semente devem ser os embriões em estádios globular (4) e cordiforme/torpedo (1), referidos na Tabela 4 . $\mathrm{O}$ fato de as três plântulas zigóticas identificadas encontrarem-se no estádio cotiledonar (Tabela 4) corroboram as afirmações de Damião Filho (1993), em que o embrião sexual durante o crescimento é projetado pelo suspensor ao endosperma, encontrando-se nesta região em estádio ulterior do desenvolvimento embrionário.

TABELA 2. Freqüiências observadas dos diferentes estádios de desenvolvimento embrionário em relação às respectivas localizações na semente. UFLA, Lavras, MG, 1997.

\begin{tabular}{lccc}
\hline Localização do & \multicolumn{3}{c}{ Estádio $^{1}$} \\
\cline { 2 - 4 } embrião & Globular & Cordiforme/torpedo Cotiledonar \\
\hline Na região micropilar & & & \\
da semente & $9(3,69)$ & $6(6,15)$ & $(6,15)$ \\
No interior da semente & $0(5,30)$ & $9(8,85)$ & $(8,85)$ \\
\hline${ }^{1}$ Frequiência esperada entre parênteses; $\chi^{2}$ calculado $=20,26(\propto<0,010)$.
\end{tabular}

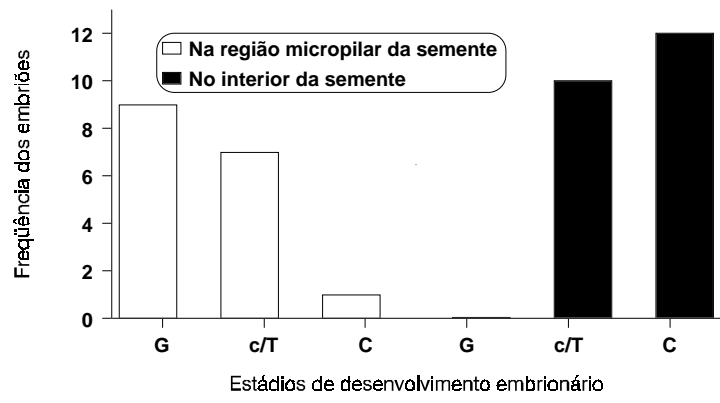

FIG. 2. Freqüência dos diferentes estádios de desenvolvimento embrionário (G-globular; c/T- cordiforme/torpedo; C- cotiledonar) após 130, 140 e 150 dias da polinização controlada. UFLA, Lavras, MG, 1997.

TABELA 3. Frequiências observadas de plântulas zigóticas e nucelares em relação às localizações dos embriões na semente. UFLA, Lavras, MG, 1997.

\begin{tabular}{lcc}
\hline Localização & \multicolumn{2}{c}{ Embrião $^{1}$} \\
\cline { 2 - 3 } & Zigótico & Nucelar \\
\hline Na região micropilar da semente & 5 & 7 \\
No interior da semente & 3 & 20 \\
\hline
\end{tabular}

$1 \propto<0,080$, pelo teste exato de Fisher. 


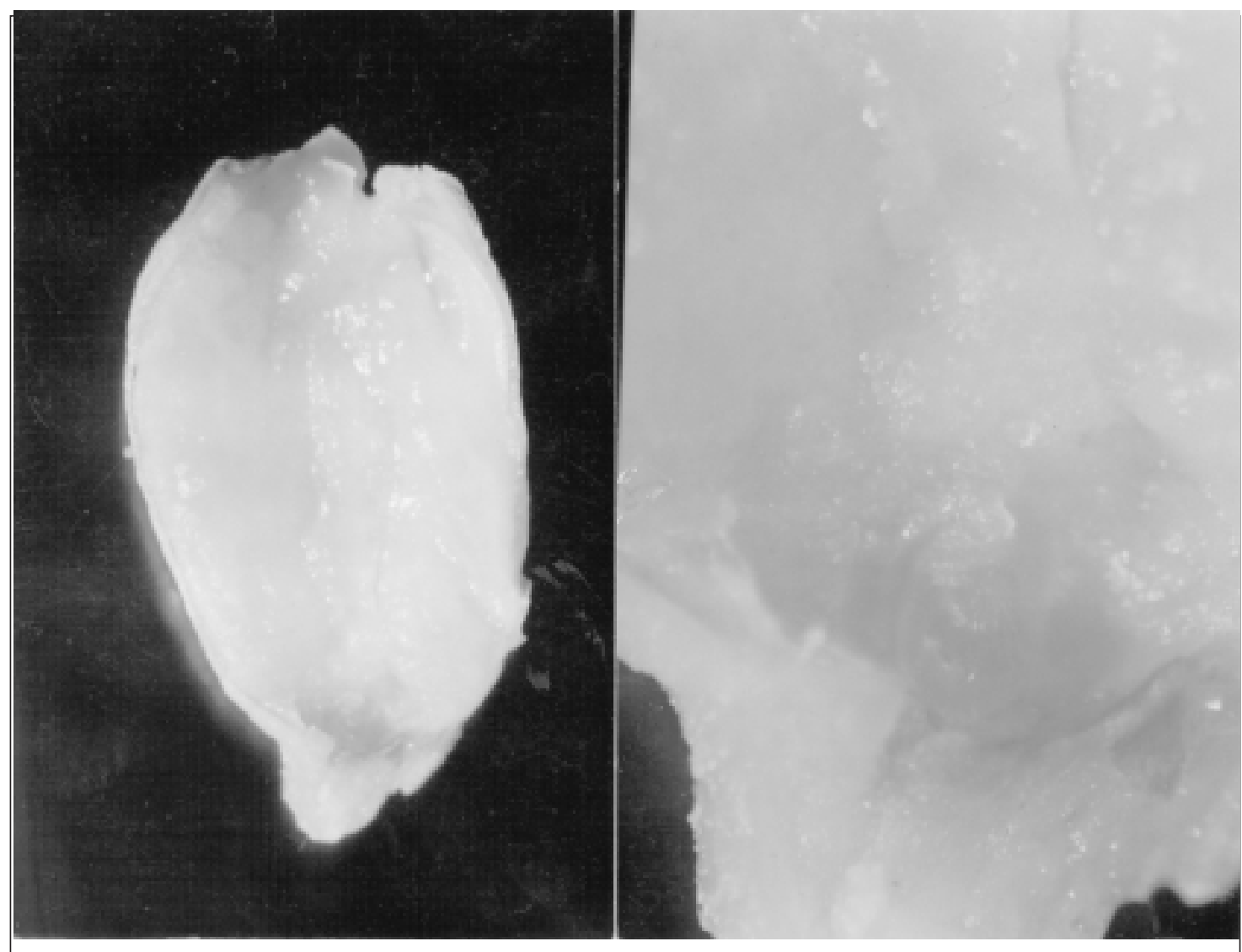

FIG. 3. Localização de embrião em estádio globular de desenvolvimento apresentando maior intumescimento e aderência aos tecidos da região micropilar da semente. UFLA, Lavras, MG, 1997.

TABELA 4. Freqüências observadas dos diferentes estádios de desenvolvimento embrionário em relação à natureza zigótica ou nucelar das plântulas. UFLA, Lavras, MG, 1997.

\begin{tabular}{cccc}
\hline \multirow{2}{*}{ Embrião } & \multicolumn{3}{c}{ Estádios dos embriões $^{1}$} \\
\cline { 2 - 4 } & Globular & Cordiforme/torpedo & Cotiledonar \\
\hline Zigótico & $4(1,60)$ & $1(2,97)$ & $3(3,43)$ \\
Nucelar & $3(5,40)$ & $12(10,03)$ & $12(11,57)$ \\
\hline \multicolumn{4}{c}{ Frequiência esperada entre parênteses; $\chi^{2}$ calculado $=6,43(\propto<0,050)}$. \\
\multicolumn{3}{c}{ CONCLUSÃO }
\end{tabular}

Embriões zigóticos em estádios de desenvolvimento globular e cordiforme, originados do cruzamento de $C$. sinensis Osb. cv. Natal com $P$. trifoliata (L.) Raf., localizam-se em maior proporção na região micropilar da semente, 130 a 150 dias após a polinização controlada.

\section{REFERÊNCIAS}

BUCK, D.K.; WALKER, D.B. Cell determination during embryogenesis in Citrus jambhiri. I. Ontogeny of the epidermis. Botanical Gazette, Chicago, v.146, n.2, p.188-195, 1985.

DAMIÃO FILHO, C.F. Morfologia vegetal. Jaboticabal: FUNEP/UNESP, 1993. 243p.

ESAN, E.B. A detailed study of adventive embryogenesis in the rutaceae. Riverside: University of California, 1973. 233p. Ph.D. Thesis.

ESAU, K. Anatomia das plantas com sementes. Tradução por Berta Lange de Morretes. São Paulo: Edgard Blucher, 1974. 293p. 
FERRI, M.G. Botânica: morfologia interna das plantas (anatomia). 9.ed. São Paulo: Nobel, 1990. 114p.

GUARDIOLA, J.L.; BARRÉS, M.T.; ALBERT, C.; GARCIA-LUIS, A. Effects of exogenous growth regulators on fruit development in Citrus unshiu. Annals of Botany, New York, v.71, n.2, p.169-176, 1993.

KOCHBA, J.; SPIEGEL-ROY, P.; SAFRAN, H. Adventive plants from ovules and nucelli in Citrus. Planta, Berlin, v.106, p.237-245, 1972.

KOLTUNOW, A.M. Apomixis: embryo sacs and embryos formed without meiosis or fertilization in ovules. The Plant Cell, Netherlands, v.5, n.10, p.14251437, 1993.

MAHESHWARI, P.; RANGASWAMY, N.S. Polyembryony and in vitro culture of Citrus and Mangifera. The Indian Journal of Horticulture, Bangalore, v.15, p.275-286, 1958.

MEDINA FILHO, H.P.; BORDIGNON, R.; BALLVE, R.M.L.; SIQUEIRA, W.J. Evidência genética da ocorrência de híbridos gêmeos mono e dizigóticos em porta-enxertos de Citrus. Revista Brasileira de Genética, Brasília, v.16, n.3, p.703-711, 1993.

MOREIRA, C.S.; PIO, R.M. Melhoramento de Citrus. In: RODRIGUEZ, O.; VIEGAS, F.; POMPEU JÚNIOR, J.; AMARO, A.A. (Eds.). Citricultura Brasileira. 2.ed. Campinas: Fundação Cargill, 1991 v.2, p.116-152.

MURASHIGE, T.; SKOOG, F. A revised medium for rapid growth and biossays with tobacco tissue cultures. Physiologia Plantarum, Copenhagen, v.15, p.473-479, 1962.
PASQUAL, M.; PINTO, J.E.B.P. Cultura de embriões. Notícias da Associação Brasileira de Cultura de Tecidos de Plantas, Brasília, v.9, p.2-12, ago. 1988.

PIMENTEL-GOMES, F. Curso de Estatística Experimental. 11.ed. São Paulo: Nobel, 1987. 446p.

RANGAN, T.S.; MURASHIGE, T.; BITTERS, W.P. In vitro studies of zygotic and nucellar embryogenesis in Citrus. In: INTERNATIONAL CITRUS SYMPOSIUM, 1. 1969, Riveside. Proceedings... Riverside: International Society of Citriculture, 1969. v.1, p.225-229.

SOARES FILHO, W. dos S.; LEE, M.; CUNHA SOBRI$\mathrm{NHO}$, A.P. da. Influence of pollinators on polyembryony in Citrus. Acta Horticulturae, v.403, p.256-265, 1995.

SOARES FILHO, W. dos S.; VÁSQUEZ ARAÚJO, J.E.; CUNHA, M.A.P. da; CUNHA SOBRINHO, A.P. da; PASSOS, O.S. Degree of polyembryony, size and survival of the zigotic embryo in Citrus. In: INTERNATIONAL CITRUS CONGRESS, 7. 1992, Acireale, Italy. Proceedings... Acireale, Italy: International Society of Citriculture, 1994. v.1, p.135138.

SPIEGEL-ROY, P.; KOCHBA, J. Embryogenesis in Citrus tissue culture. In: FIECHTER, A. (Ed.). Advances in biochemical engineering. Berlin: SpringerVerlang, 1980. p.27-48.

TALON, M.; ZACARIAS, L.; PRIMO-MILLO, E. Gibberellins and pathernocarpic ability in developing ovaries of seedless mandarins. Plant Physiology, Washington, v.99, n.4, p.1575-1581, 1992.

WAKANA, A.; UEMOTO, S. Adventive embryogenesis in Citrus (Rutaceae). II. Postfertilization development. American Journal of Botany, Miami, v.75, n.7, p.1033-1047, 1988. 